\title{
Equity of access to reproductive health services among youths in resource-limited suburban communities of Mandalay City, Myanmar
}

\author{
Phyu Phyu Thin Zaw ${ }^{1 *}$, Tippawan Liabsuetrakul ${ }^{2}$, Thien Thien Htay ${ }^{3}$ and Edward McNeil ${ }^{2}$
}

\begin{abstract}
Background: Inequity of accessibility to and utilization of reproductive health $(\mathrm{RH})$ services among youths is a global concern, especially in resource-limited areas. The level of inequity also varies by cultural and socio-economic contexts. To tailor RH services to the needs of youths, relevant solutions are required. This study aimed to assess baseline information on access to and utilization of RH services and unmet needs among youths living in resourcelimited, suburban communities of Mandalay City, Myanmar.
\end{abstract}

Methods: A community-based, cross-sectional study was conducted in all resource-limited, suburban communities of Mandalay City, Myanmar. A total of 444 randomly selected youths aged between 15 and 24 years were interviewed for three main outcomes, namely accessibility to and utilization of RH services and youth's unmet needs for these services. Factors associated with these outcomes were determined using multivariate logistic regression.

Results: Although geographical accessibility was high (79.3\%), financial accessibility was low (19.1\%) resulting in a low overall accessibility (34.5\%) to RH services. Two-thirds of youths used some kind of RH services at least once in the past. Levels of unmet needs for sexual RH information, family planning, maternal care and HIV testing were $62.6 \%, 31.9 \%, 38.7 \%$ and $56.2 \%$, respectively. Youths living in the south or south-western suburbs, having a deceased parent, never being married or never exposed to mass media were less likely to access RH services. Being a young adult, current student, working as a waste recycler, having ever experienced a sexual relationship, ever being married, ever exposed to mass media, having a high knowledge of RH services and providers or a high level of accessibility to RH services significantly increased the likelihood of utilization of those services. In addition to youths' socio-demographic characteristics, exposure to mass media, norm of peer exposure and knowledge on types of providers and services significantly influenced the unmet needs of youths towards RH services.

Conclusion: Despite the availability of RH services, youth's accessibility to and utilization of those services were unsatisfactory. The levels of youths' unmet RH needs were alarmingly high.

Keywords: Equity, Reproductive health, Youth, Accessibility, Utilization, Unmet need

\footnotetext{
* Correspondence: drphyu.pptz@gmail.com

'Department of Medical Research (Upper Myanmar), Pyin Oo Lwin, Myanmar

Full list of author information is available at the end of the article
} 


\section{Background}

Youths, defined as individuals aged between 15 to 24 years, constitute $18 \%$ of the world's population, of which nearly $80 \%$ live in developing countries [1]. All youths have their own rights to access available reproductive health $(\mathrm{RH})$ services and achieve a healthy reproductive life [2], which is also a keystone to achieving the Millennium Development Goals (MDG target 5b). Although $\mathrm{RH}$ services are important to youths, the accessibility to and utilization of $\mathrm{RH}$ services among youths are very limited due to various socio-economic and cultural disparities [3-5].

Low accessibility to and utilization of RH services creates a universal concern since unintended pregnancies, unsafe abortions, and sexually transmitted infections (STIs) have been shown to contribute to high morbidity and mortality rates, especially in developing countries [6-10]. Globally, approximately 16 million adolescents become pregnant every year, of which three million undergo unsafe abortions [11]. Adolescents are more likely to die from the causes related to pregnancy and childbirth compared to reproductive-aged women [11-13]. Likewise, the stigmatization of premarital sexual relations among young women deters them from seeking information about RH, engaging in safer sex and fulfilling their RH needs [14]. Those disparities of access to $\mathrm{RH}$ care affect not only the individuals but also their families, society and health systems as a whole at both national and global levels $[15,16]$. Therefore, the inequity of access to RH services between the rich and the poor, and those living in urban and rural areas are a global equity issue of high priority.

Although the availability of RH services has been promoted globally, the disparities of access to $\mathrm{RH}$ care still remain among youths, especially those living in resource-limited areas $[17,18]$. In addition, youth's accessibility to and utilization of $\mathrm{RH}$ services and their unmet needs for these services are influenced by various cultural and socio-economic contexts [19]. This study aimed to assess the level of accessibility to, utilization of and unmet needs for $\mathrm{RH}$ services and to identify the associated factors with respect to individual, family and various socio-economic characteristics among youths in resource-limited communities in suburban areas of Mandalay City, Myanmar.

\section{Methods}

\section{Study area}

Myanmar is located in South-East Asia, bordered by India, Bangladesh, China, Thailand and Laos. It is listed by WHO as a low-income country with an average GDP of $\$ 821$. Of the 60 million residents, $32.7 \%$ have an income under the international poverty line [20]. Mandalay City, situated in central Myanmar, is a densely populated area with relatively low cultural, racial and social heterogeneity. There are 10 resource-limited communities situated in suburban areas of the city which are enriched with hardto-reach, informal settings and residents with a low socioeconomic status. All areas of Mandalay City are covered by $\mathrm{RH}$ projects and the availability of $\mathrm{RH}$ services has been ascertained; however, it is not known whether youths living in these areas have sufficient access to those $\mathrm{RH}$ services. Likewise, understanding their exact $\mathrm{RH}$ needs in order to tailor services to those needs remains a challenge for policy makers since there has been no previous study focusing on this vulnerable group.

\section{Study design and participants}

A community-based, cross-sectional study was conducted from May 2011 to September 2011. Male and female youths aged between 15-24 years residing in any of the 10 resource-limited, suburban communities of Mandalay City were included in the study. Those who were not available for interviews or unwilling to participate in the study were excluded. The sample size was calculated based on an estimated utilization of RH services of $50 \%$ and adjusted for a $10 \%$ rate of incomplete information. Because of perceived variation of utilization levels among the different communities and between males and females, a design effect of 2 was also employed. Thus at least 215 female and 215 male youths, or a total of 430 youths, were required to estimate the utilization level with an accuracy of $10 \%$.

\section{Data collection}

\section{Preparatory phase}

The focus of the study was to estimate accessibility, utilization and unmet needs for $\mathrm{RH}$ services among youths. The study participants were interviewed using a structured questionnaire which was separated into five sections: socio-demographic characteristics and four main aspects of RH services (sexual RH (SRH) information, family planning, maternal care, STI/HIV testing). The questionnaire was developed based on several literature reviews on measuring accessibility [21-26], and the 2007 Indonesia Demographic and Health Survey (IDHS) which was undertaken as part of the international Demographic and Health Surveys project. The questionnaire from the IDHS is designed to collect data on fertility, family planning and maternal and child health [27].

The questionnaire was developed in English and backtranslated from English to Burmese and English again by two independent translators. The meanings of all items in the questionnaire were checked accordingly and face validity was assessed. The interpretability and understanding of all items by the study participants were evaluated by pre-testing the questionnaire on 20 youths living in the study area but who were not included in 
the main study and the items were modified qualitatively. Six interviewers (3 females and 3 males) were trained on using a rapport approach and on how to conduct interviews. The interview process was standardized among all interviewers before data collection commenced.

\section{Sampling methods}

Youths, in accordance with the inclusion and exclusion criteria in each community, were selected by simple random sampling. The process of sampling was conducted using the following steps. Firstly, all 10 resource-limited communities in all townships of Mandalay City were identified and confirmed by the township medical officers (TMOs). Secondly, lists of youths living in these communities were obtained from the community leaders. Thirdly, in each community, a roughly equal number of males and females were randomly selected using a random number generator based on the sex-stratified lists of youths living in each community. Finally, the appointments between the selected youths and the interviewers were made with the facilitation of community leaders.

\section{Data collection phase}

The interviewers went to the youths' houses at the scheduled appointment dates and times and conducted the interviews. For those who were not available at the first appointment, a second appointment was made. Before the interviews, all youths were informed about the objectives of the study and a signed consent form was obtained from each one. Privacy, anonymity and confidentiality were maintained throughout the process of this study. Discussions among the interviewers were made on a daily basis to check the accuracy of data.

\section{Outcome measures}

The outcome measures were overall accessibility to $\mathrm{RH}$ services, overall utilization of $\mathrm{RH}$ services and youth's unmet needs for the four $\mathrm{RH}$ components mentioned previously.

\section{Accessibility to $\mathrm{RH}$ services}

The accessibility in our study applied both geographical and financial considerations based on the youths' own perception. Youths who lived within a 30-minute walk and within a one-mile distance from the nearest RH service centre from their home, and were aware that the service existed, were classified as having high geographical accessibility. For financial accessibility, we considered three aspects: travelling costs, service costs (drug fees, consultant fees) and youth's perception of affordability. High financial accessibility was defined as a cost of travel less than 500 kyat (\$0.63) and a cost of service less than 1500 kyat (US\$1.9) with a perceived affordability of all costs. Youths having both high geographical and high financial accessibility were classified as having high overall accessibility and low accessibility otherwise.

\section{Utilization of RH services}

Four essential components of RH services were assessed, namely SRH information services (any health education sessions/talks/classes that emphasized on SRH given in schools, clinics, or other places involving peer-based education excluding mass media), family planning services, comprehensive maternal care services (at least one antenatal care (ANC) visit, delivery by skilled birth attendance (SBA) and at least one postnatal care visit) and STI/HIV testing services.

Overall utilization of $\mathrm{RH}$ services was classified as the youths having sought or received at least one of the above four RH services. For SRH information and family planning, utilization must have been within the past 6 months for the youth to be classified as having utilized the service. For maternal health services and STI/HIV testing, if the youth used these services anytime in their life, they were classified as having utilized that service.

\section{Unmet RH needs}

\section{Unmet need for SRH information}

All four RH components were evaluated for individual unmet needs. Since all youths have a right to access and utilize all SRH information services at any time in their life, unmet need for SRH information was defined as any youth who never utilized any SRH information service.

\section{Unmet need for family planning}

The standard definition given by WHO of unmet need for family planning applies to married and reproductive aged women only [28]. However, nowadays the need for family planning is discussed among women and their partners who are not ready to conceive, regardless of their marital status. As a result, unmet need for family planning in this study was defined as any currently nonpregnant, sexually active female youth (defined as having a current sexual partner and having sex with that partner) who did not use contraception, even though she did not intend to conceive. Intention to conceive was determined by asking the following question. "Do you have a sexual partner?" Those responding in the affirmative were further asked, "Are you currently having sex with that partner?" Those responding in the affirmative were further asked the following two questions: " $D o$ you use any type of contraception?" and "Do you want to conceive in the near future?" Youths who responded "no" to the last question were classified as not intending to conceive. 


\section{Unmet need for maternal care}

Any female youth who had been pregnant at least once and had never received comprehensive maternal care (defined as receiving all three components of maternal care) was defined as having an unmet need for maternal care.

\section{Unmet need for STI/HIV testing}

In this study, unmet need for STI/HIV testing was defined as any youth who had ever had sex without using a condom and had never been tested for STI/HIV. In addition, youths who did not use any RH service were asked, using an open-ended question, for their reason. The reasons were presented descriptively after coding and summarizing.

\section{Independent variables}

Independent variables included demographic and socioeconomic characteristics, reproductive characteristics and family characteristics. Demographic and socio-economic characteristics included age, gender, ethnicity, religion, place of residence, schooling status, level of education, occupation, personal income, knowledge of RH services and types of providers, perceived norm of peer exposure to RH services, and exposure to any mass media on SRH via resources such as books, television, radio, or the Internet (never versus ever in their life). Youths were classified as either adolescent (age 15-19) or young adult (age 20-25). Education level was classified as none, low (less than secondary), middle (secondary) or high (more than secondary). Occupations were classified into 3 categories: unemployed (dependent/housewife/jobless), waste recycler (people who wander and collect used material all over the city and sell them to the recycling factories) and other employed (shopkeeper/municipal worker/labourer). Because waste cyclers were so common, their occupation was singled out. The international poverty line of $\$ 37.5$ or 30,000 kyat (800 kyat per $\$ 1$ ) was used as the threshold for a low personal income. Knowing the available types of services and types of providers within the area was regarded as knowledge of $\mathrm{RH}$ services and providers. Knowledge score was calculated by asking each youth if they knew of the available types of RH services and providers in their local area, which included a total of five types of services and eight types of providers. For each known type of service or provider, a youth was given one point reflecting a maximal score of 13. If the youths responded that his/her friends or relatives utilized any type of RH services, the perceived norm of peer exposure to RH services was classified as "yes". Reproductive characteristics included past sexual experience, marital status, and pregnancy status. Family characteristics included parental status (alive or dead) and educational level, household income and number of family members.

\section{Statistical analysis}

The percentages of accessibility to $\mathrm{RH}$ services, utilization of RH services, and unmet needs for the four SRH components were presented descriptively. The association between independent variables and the three main outcome measures was initially assessed by univariate analysis. Independent variables which had a $p$-value of less than 0.2 were included in the multivariate logistic regression analysis. Statistical significance was considered if a variable had a $p$-value less than 0.05 in the final model. All analysis was done using $\mathrm{R}$.

\section{Ethical considerations}

The proposal was approved by the Institutional Ethics Committee of the Faculty of Medicine, Prince of Songkla University, Hat Yai, Thailand and the Ethics Committee of the Department of Medical Research (Upper Myanmar) before the study was conducted. All eligible youths were informed of their right to participate in the study using informed consent and their anonymity and confidentiality was stringently maintained throughout the study.

\section{Results}

\section{Socio-demographic characteristics}

All sampled youths agreed to participate in the study and completed the interviews for a response rate of $100 \%$. The demographic, socio-economic, reproductive and family characteristics of the youths are shown in Table 1. Of 444 youths interviewed, 215 were males and 229 were females. Among them, 231 (52\%) were adolescents and $213(48 \%)$ were young adults. Almost all were Buddhists and of Bamar ethnicity. Most (88\%) were out of school, and very few attained a high-school level of education. Unemployment rate was considerably high (21\%). One-fourth worked as waste recyclers. The personal income of the youths was very low and nearly half had an income under the international poverty line. Although there was a high prevalence of positive perceived norm of peer exposure to $\mathrm{RH}$ services, the youths had very little knowledge of available types of provider and RH services in their communities. Nearly one-third had never accessed any type of mass media (books/magazines, TV, radio or the Internet) for information on $\mathrm{RH}$. More than half $(53 \%)$ had a history of sexual exposure and less than half (44\%) had ever been married. The majority $(70 \%)$ of the youths, or their spouses, had never been pregnant. One-fourth of the youths had one deceased parent (mostly their fathers, who passed away before age fifty). Parental education level was mostly low. The average household income was US\$ 178. 
Table 1 Characteristics of youths

Factor

Age group

$\begin{array}{ll}\text { Adolescents } & 231(52.0) \\ \text { Young adults } & 213(48.0) \\ \text { Sex } & \\ \text { Male } & 215(48.4) \\ \text { Female } & 229(51.6)\end{array}$

Ethnic group

$\begin{array}{cc}\text { Bamar } & 437(98.4) \\ \text { Other } & 7(1.6)\end{array}$

Religion

Buddhist

Other

$438(98.6)$

$6(1.4)$

Place of residence

$\begin{array}{lc}\text { East } & 93(20.9) \\ \text { North-west } & 50(11.3) \\ \text { West } & 99(22.3) \\ \text { South-west } & 40(9) \\ \text { South } & 128(28.8) \\ \text { South-east } & 34(7.7) \\ \text { Schooling status } & \\ \text { In-school } & 54(12.2) \\ \text { Out-of-school } & 390(87.8)\end{array}$

Education

$\begin{array}{lc}\text { None } & 25(5.6) \\ \text { Low } & 192(43.2) \\ \text { Middle } & 128(28.8) \\ \text { High } & 99(22.3)\end{array}$

Occupation

$\begin{array}{lc}\text { Unemployed } & 92(20.7) \\ \text { Waste recycler } & 103(23.2) \\ \text { Other employed } & 249(56.1)\end{array}$

Personal income (US\$)

$\begin{array}{ll}\leq 37.5 & 175(39.4) \\ >37.5 & 269(60.6)\end{array}$

\section{Factor}

n (\%)

Reproductive characteristics

Sexual exposure

Never exposed

$209(47.1)$

Ever exposed

$235(52.9)$

Marital status

Never married

$250(56.3)$

Ever married

$194(43.7)$

Pregnancy status*

Never pregnant

$313(70.5)$

Ever pregnant

$109(24.5)$

Currently pregnant

$22(5.0)$

Knowledge, perception and media exposure

Perceived norm of peer exposure

$\begin{array}{lc}\text { No } & 55(12.4) \\ \text { Yes } & 389(87.6) \\ \text { Knowledge of RH services and providers } & \\ \text { Mean (SD) } & 3.3(1.6) \\ \text { Media exposure } & \\ \text { Ever exposed } & 302(68.0) \\ \text { Never exposed } & 142(32.0)\end{array}$

\section{Family characteristics}

Parental status

Both alive

$281(63.2)$

One or more deceased

$163(36.8)$

Father's education level

None

$96(21.6)$

Low

$259(58.3)$

Middle and above

$89(20.1)$

Mother's education level

None $\quad 93(20.9)$

Low $\quad 320$ (72.1)

Middle and above 31 (7.0)

Household income (US\$)

Mean (SD)

$178(96.1)$

Number of family members

$\leq 5$ persons

$246(55.4)$

$>5$ persons

* For males, responses are for their spouses or partners. 


\section{Accessibility to $\mathrm{RH}$ services}

The majority of the participants said that there was at least one $\mathrm{RH}$ service centre within a 30-minute walk (94\%) and within one mile (80\%) from their home. The most common mode of transportation to the RH centre was by foot (83\%). Only $5 \%$ said that the service was free of charge, $20 \%$ said that they had to pay less than $\$ 1.29$, while $75 \%$ said that they had to pay more than $\$ 1.29$. Based on the youth's self perception, $69 \%$ thought that all costs (travelling and service) were not affordable.

A summary of the geographical, financial and overall accessibility and utilization levels for males and females are presented in Table 2. Most had a high level of geographical accessibility (79\%) and a low level of financial accessibility (81\%). Most had a low overall level of accessibility (66\%). There was no difference between males and females in all three aspects of accessibility.

Table 3 shows the final model of factors associated with overall accessibility. Youths living in the south (adjusted OR (AOR) 0.29, 95\% confidence interval (CI) 0.16-0.52) or south-western (AOR 0.36, 95\% CI 0.150.84 ) suburbs, having one or more deceased parent (AOR 0.5, 95\% CI 0.31-0.81), never being married (AOR $0.57,95 \% \mathrm{CI} 0.36-0.90)$ or having never been exposed to mass media (AOR 0.55, 95\% CI 0.35-0.86) were less likely to have a high overall accessibility to RH services.

\section{Utilization of RH services}

Of the 444 youths, $67 \%$ had ever utilized at least one type of RH service. The most utilized service was family planning (70\%). Common service providers were midwives (39\%) and non-governmental organizations (NGOs) (22\%). Table 4 depicts the factors associated with the overall utilization of any RH services. Being a young adult, current student, working as a waste recycler, having a

Table 2 Comparison of accessibility and utilization between male and female youths

\begin{tabular}{|c|c|c|c|}
\hline & Male, n (\%) & Female, n (\%) & Total, n (\%) \\
\hline \multicolumn{4}{|c|}{ Geographical accessibility } \\
\hline Low & 47 (21.9) & $45(19.7)$ & $92(20.7)$ \\
\hline High & $168(78.1)$ & $184(80.3)$ & $352(79.3)$ \\
\hline \multicolumn{4}{|c|}{ Financial accessibility } \\
\hline Low & $170(79.1)$ & $189(82.5)$ & $359(80.9)$ \\
\hline High & $45(20.9)$ & $40(17.5)$ & $85(19.1)$ \\
\hline \multicolumn{4}{|c|}{ Overall accessibility } \\
\hline Low & $140(65.1)$ & $151(65.9)$ & $291(65.5)$ \\
\hline High & 75 (34.9) & $78(34.1)$ & $153(34.5)$ \\
\hline \multicolumn{4}{|c|}{ Overall utilization } \\
\hline No & $84(39.1)$ & $62(27.1)$ & $146(32.9)$ \\
\hline Yes & $131(60.9)$ & $167(72.9)$ & $298(67.1)$ \\
\hline
\end{tabular}

Table 3 Factors significantly associated with overall accessibility to RH services

\begin{tabular}{lcc}
\hline Factor & $\begin{array}{c}\text { Adjusted OR } \\
\mathbf{9 5 \%} \mathbf{C l})\end{array}$ & $\begin{array}{c}\text { P- } \\
\text { value }^{*}\end{array}$ \\
\hline Youth's place of residence: ref.= East & & $<0.001$ \\
$\quad$ North-west & $0.52(0.25-1.08)$ & \\
West & $1.05(0.60-1.83)$ & \\
South-west & $0.36(0.15-0.84)$ & \\
South & $0.29(0.16-0.52)$ &
\end{tabular}

Parental status: ref.= Both alive

One or both deceased

$0.50(0.31-0.81)$

Youth's marital status: ref.= Ever married

Never married

$0.57(0.36-0.90)$

Youth's media exposure: ref.= Ever exposed

Never exposed

$0.55(0.35-0.86)$

Factors included in the initial model were age group, personal income, father's education, mother's education and history of sexual exposure.

OR: Odds Ratio; Cl: Confidence Interval; * Likelihood ratio test.

history of sexual exposure, ever being married, exposure to mass media, having a high knowledge of $\mathrm{RH}$ services and providers or having a high level of accessibility to $\mathrm{RH}$ services significantly increased the likelihood of utilizing those services. The difference in utilization between males and females was statistically significant (Table 2).

Table 4 Factors significantly associated with utilization of at least one RH service

\begin{tabular}{|c|c|c|}
\hline Factor & $\begin{array}{l}\text { Adjusted OR } \\
(95 \% \mathrm{Cl})\end{array}$ & $\begin{array}{c}\text { P- } \\
\text { value* }\end{array}$ \\
\hline Age group: ref $=$ Adolescents & & 0.039 \\
\hline Young adults & $1.82(1.03-3.22)$ & \\
\hline Schooling status: ref $=$ Out-of-school & & $<0.001$ \\
\hline In-school & $5.88(2.44-14.28)$ & \\
\hline Occupation: ref $=$ Unemployed & & 0.003 \\
\hline Waste recycler & $4.00(1.67-9.58)$ & \\
\hline Employed & $1.68(0.82-3.45)$ & \\
\hline Sexual exposure: ref = Never exposed & & 0.006 \\
\hline Ever exposed & $3.12(1.35-7.24)$ & \\
\hline Marital status: ref $=$ Never married & & 0.004 \\
\hline Ever married & $3.72(1.55-8.91)$ & \\
\hline Media exposure: ref $=$ Never exposed & & 0.006 \\
\hline Ever exposed & $2.20(1.25-3.86)$ & \\
\hline Knowledge of RH services and providers & $1.43(1.18-1.73)$ & $<0.001$ \\
\hline Overall accessibility: ref $=$ Low & & 0.013 \\
\hline High & $1.96(1.14-3.36)$ & \\
\hline
\end{tabular}

Factors included in the initial model were sex, place of residence, education attainment, personal income, parental status, father's education, mother's education, pregnancy status and perceived norm on peer exposure. OR: Odds Ratio; Cl: Confidence Interval; * Likelihood ratio test. 


\section{Unmet RH needs}

\section{Unmet need for SRH information}

The level of unmet need for SRH information was $67 \%$. Of all youths, 33\% had accessed or received SRH information in their lifetime, of which NGOs were the most common providers (67\%). Youths who had attended RH education sessions said that the most common types of information provided were for STI/HIV (90\%) and contraceptives (46\%). The main reasons of non-exposure to $\mathrm{SRH}$ information were the youth's own feeling of embarrassment and negative attitudes of the youth's guardians.

\section{Unmet need for family planning services}

Of 113 sexually active female youths who were currently neither pregnant nor intending to be pregnant, 36 were not using any form of contraceptive, giving a level of unmet need for family planning services of $32 \%$. Of the 77 who were currently using contraceptives, the most common types of contraceptives used were depot injections (51\%) and oral contraceptive pill (26\%). Family planning service centres utilized by the youths included private clinics (21\%), midwives (17\%), drug stores (13\%) and NGOs (11\%). Common reasons for not utilizing family planning services were an inability to pay for the services and confidentiality concerns of unmarried youths. Less common reasons included inconvenience of transportation, as well as negative attitudes of providers.

\section{Unmet need for maternal care services}

The rate of unmet need for comprehensive maternal care was 39\%. Out of 75 female youths who had ever been pregnant, $13 \%$ had never received antenatal care (ANC), 17\% had deliveries that were never assisted by an SBA and $25 \%$ had never received postnatal care. Common reasons for not utilizing comprehensive maternal care services were inability to pay for the service and inconvenience of transportation.

\section{Unmet need for STI/HIV testing}

Among 119 youths who had had unprotected sexual encounters, the level of unmet need for STI/HIV testing was $50 \%$. Of those who had been tested, the usual places were urban health centres (32\%), the STI clinic of Mandalay General Hospital (29\%) and NGOs (26\%). Common reasons for having STI/HIV tests were pregnancy $(54 \%)$, curiosity (14\%) and having practised a risky sexual behaviour (14\%). The most common reason for not having an STI/HIV test was lack of perceived need to do so. Less common reasons were fear of getting a positive test result, embarrassment, not knowing the location of the testing facility, and inability to pay for the service.

\section{Factors associated with unmet needs for RH services}

Table 5 shows factors associated with unmet needs for all four components of RH services. A lower unmet need for SRH information was found among young adults (AOR 0.55, 95\% CI 0.34-0.91), youths who had a high accessibility to RH services (AOR 0.61, 95\% CI 0.39 $0.94)$ and a high knowledge of $\mathrm{RH}$ services and providers (AOR 0.78, 95\% CI 0.68-0.90), while out-of-school youths were more likely to have an unmet need for SRH information (AOR 4.47, 95\% CI 2.30-8.68).

Preventative factors significantly associated with unmet need for family planning were being married (AOR 0.09, 95\% CI 0.01-0.97), exposure to mass media (AOR $0.21,95 \%$ CI $0.05-0.83$ ) and having a high knowledge of $\mathrm{RH}$ services and providers (AOR 0.61, 95\% CI 0.410.89).

Youths who lived in a family having more than 5 family members had a higher likelihood of having an unmet need for maternal health services (AOR 2.60, 95\% CI 1.25-5.37) while those who had a perceived norm of peer exposure to $\mathrm{RH}$ services had a lower likelihood (AOR 0.09, 95\% CI 0.01-0.76).

Youths who lived in the south (AOR 3.16, 95\% CI 1.40-7.16) or south-western (AOR 5.14, 95\% CI 1.6815.75) suburbs had a higher unmet need for STI/HIV testing services, whereas preventive factors were being a young adult (AOR 0.43, 95\% CI 0.21-0.86), having a perceived norm of peer exposure to RH services (AOR 0.16, 95\% CI 0.05-0.54) and having a high knowledge of $\mathrm{RH}$ services and providers (AOR 0.72, 95\% CI 0.59-0.88).

\section{Discussion}

Although the level of accessibility to reproductive health services by geographical assessment among youths in our study was high, the financial accessibility was low reflecting a low overall level of utilization of all $\mathrm{RH}$ services. Unmet needs for $\mathrm{RH}$ services were consistently high for all four aspects. In addition to youth's individual and socio-economic characteristics, some important factors such as exposure to mass media, knowledge of $\mathrm{RH}$ services and providers and perceived norm of peer exposure to $\mathrm{RH}$ services, significantly influenced the youth's accessibility to and utilization of RH services and their unmet needs for these services.

A low level of accessibility to $\mathrm{RH}$ services due to financial aspects was found in our study although the geographical accessibility was adequate. Geographic and financial assessments are commonly used for measuring accessibility to health care services; however, the methods of measurement vary $[29,30]$. Accessibility to health care is influenced not only by geographical but also by social, psychological, economic and organizational factors [22,23]. Geographical Information Systems (GIS) have been commonly used to measure physical 
Table 5 Factors significantly associated with unmet needs for RH services

\begin{tabular}{|c|c|c|c|c|}
\hline \multirow[t]{2}{*}{ Factor } & SRH information & Family planning & Maternal care & HIV/STD testing \\
\hline & OR $(95 \% \mathrm{Cl})$ & OR $(95 \% \mathrm{Cl})$ & OR $(95 \% \mathrm{Cl})$ & OR (95\% CI) \\
\hline Age group: ref. $=$ Adolescents & & - & - & \\
\hline Young adults & $0.55(0.34-0.91) \dagger$ & & & $0.43(0.21-0.86) \dagger$ \\
\hline Youth's residence: ref. = East & - & - & - & \\
\hline North-west & & & & $1.40(0.49-4.01)$ \\
\hline West & & & & $0.75(0.33-1.7)$ \\
\hline South- west & & & & $5.14(1.68-15.75) \neq$ \\
\hline South & & & & $3.16(1.40-7.16) \neq$ \\
\hline Schooling status: ref. $=$ In-school & & - & - & - \\
\hline Out-of-school & $4.47(2.30-8.68)^{*}$ & & & \\
\hline Marital status: ref $=$ Never married & - & & - & - \\
\hline Ever married & & $0.09(0.01-0.97)^{*}$ & & \\
\hline Number of family members: ref $=\leq 5$ persons & - & - & & - \\
\hline$>5$ persons & & & $2.6(1.25-5.37) \neq$ & \\
\hline Overall accessibility: ref $=$ LoW & & - & - & - \\
\hline High & $0.61(0.39-0.94) \dagger$ & & & \\
\hline Media exposure: ref $=$ Never exposed & - & & - & - \\
\hline Ever exposed & & $0.21(0.05-0.83) \dagger$ & & \\
\hline Knowledge on RH services & $0.78(0.68-0.90)^{*}$ & $0.61(0.41-0.89) \neq$ & - & $0.72(0.59-0.88)^{*}$ \\
\hline Perceived norm of peer exposure to $\mathrm{RH}$ services: $r$ f $=\mathrm{No}$ & - & - & & \\
\hline Yes & & & $0.09(0.01-0.76) \neq$ & $0.16(0.05-0.54)^{*}$ \\
\hline
\end{tabular}

Notes: $\uparrow \mathrm{p} \leq 0.05 ; \neq \mathrm{p} \leq 0.01 ;{ }^{*} \mathrm{p} \leq 0.001$ (Likelihood ratio test) OR: Odds Ratio; Cl: Confidence Interval.

Factors included in each initial model were sex, education attainment, occupation, personal income, parental status, father's education, mother's education, household income, history of sexual exposure, pregnancy status.

accessibility [10,31]; however, financial considerations and client's perceptions of their own access have been lacking. Even if geographical accessibility of health services is adequate, the youths won't access them unless they know that they exist. Other studies have suggested that the perception of a client's own geographical and financial access to health care is also important regardless of actual time or distance involved in reaching the service [22-25]. Therefore, accessibility in our study applied both geographical and financial considerations based on the youths' own perceptions. Methods used to measure accessibility in our study were quite similar to those from the studies conducted in Thailand, Tanzania and Nepal $[22,23,26]$.

We found that geographical accessibility was satisfactory in our study compared to other studies [21-23,26]. To date, little information is available on issues of accessibility to RH services in Myanmar. However, an RH report from the Ministry of Health, Myanmar, which surveyed three townships during 1991 to 2001, mentioned that the distance and travelling time were not the main barriers of access to RH services whereas financial impoverishment hindered utilization of contraceptives among the poor [32]. These findings indicate that inaccessibility to $\mathrm{RH}$ services due to the financial aspects has been present for a decade. In contrast to our study, distance and travelling time from home to $\mathrm{RH}$ services remain important barriers in rural areas of Nepal, the Philippines and Malawi [26,33,34]. Low accessibility to RH services among the poor youths due to a lack of affordability in our study highlighted the inequity of access to $\mathrm{RH}$ services between the rich and the poor, and the rural and urban dwellers as found in previous studies $[8,35,36]$. In addition, our study confirmed the finding from other studies that low accessibility to $\mathrm{RH}$ services results in low utilization of those services $[25,26,37,38]$.

The measurement of utilization of $\mathrm{RH}$ services varies widely. Some studies used just one aspect of RH services [39-42] while others used multiple aspects [43-45]. However, very few studies assessed all four essential aspects of RH services as we did in our study. Even among few studies which considered multiple aspects of $\mathrm{RH}$, the services assessed varied. In 3 studies conducted in the USA [43-45], the level of utilization was found to be similar to our study; however, the American studies included utilization of $\mathrm{RH}$ services that were not assessed in our study, such as PAP smear, pelvic examination and abortions services. 
In our study, the level of unmet need for family planning was higher than that among reproductive-aged women in Myanmar and other South East Asian countries [46,47] but lower than that in Pakistan [48]. Inability to pay was the main reason for youths in our study to have a higher unmet need for family planning compared to women from other South East Asian countries. Religious beliefs deterred women in Pakistan from using contraceptives causing them to have a higher unmet need for family planning.

There is currently no standard definition of unmet needs for SRH information, comprehensive maternal care and STI/HIV testing service. No previous study has assessed the levels of unmet need for those services; therefore no comparison can be made. In our study, we calculated those unmet needs based on the actual needs of youths. A broad approach to defining actual needs for those $\mathrm{RH}$ services is warranted so that the unmet needs can be calculated in the future. However, youths' perceived needs of those services also played a major role. In our study, we found that a majority of the youths wanted to receive SRH information and maternal care services even though they perceived that they could not afford them or were too embarrassed to use the service. In contrast, a majority of youths who had had sex without using any condoms to prevent STI/HIV lacked a perceived need to receive STI/HIV testing despite their actual need for it.

In general, the factors associated with accessibility to, utilization of, and unmet needs for $\mathrm{RH}$ services were interrelated. Youths living in the south and southwestern suburbs of Mandalay City had a lower level of accessibility and a higher unmet need for HIV testing services. Possible explanations are that the communities in these areas are newly settled, and have poor road conditions, especially in the rainy season, compared to other areas. This fact was supported by the youth's stated barriers for utilization of $\mathrm{RH}$ services, i.e. difficulties with transportation. A higher utilization of RH services among married youths or those who were in a sexual relationship might be due to them having good spousal communication [49] or perception of their susceptibility of RH problems as their perceived needs [50].

In our study, adolescents and out-of-school youths had a significantly lower utilization and higher unmet needs for SRH information. SRH information is usually obtained in the regular school-based SRH education classes in Mandalay City, thus out-of-school youths have fewer opportunities to access this information [51]. In addition, adolescents' own embarrassment and negative attitudes of their guardians have been shown to be common barriers to access SRH information services [14,19,52], findings which were similar to ours.

Youths who had never been married had a significantly lower utilization and higher unmet need for family planning. A concern about confidentiality by unmarried youths was the main barrier to access the service in our study as well as in many other studies [53-55]. The perception on society's and providers' negative attitudes on receiving the service is also an important barrier $[55,56]$. Fulfilling the need for family planning services among unmarried youths is critical since the rate of unwanted pregnancy and unsafe abortion among unmarried youths each year is alarmingly high $[53,57]$. A higher likelihood of $\mathrm{RH}$ utilization was found among youths working as waste recyclers compared to the unemployed in our study. One reason could be due to the active involvement of NGOs and government assigned midwives who provide $\mathrm{RH}$ services to the areas where this vulnerable group live.

In our study, we found that family factors, as well as individual and reproductive factors, played an important role in youths' utilization of RH services. Youths who had one deceased parent and those who had more than five family members were less likely to utilize the services. This finding was supported by one study that found that the relationship between youths and their parents, as well as childhood family conditions, influenced the youth's utilization of RH services [44]. Moreover, having a high number of family members in the household may increase the financial burden of the youth's family.

The finding that a higher knowledge of available $\mathrm{RH}$ services by the youths increased their odds of utilizing those services was supported by a similar study in Ethiopia which measured youths' knowledge of RH services and providers [58]. If the youths are more aware of the services and providers in their local area, they are more likely to use those services.

Perceived norm of peer exposure to RH services was significantly associated with lower unmet need for maternal care and STI/HIV testing, a finding similar to a study conducted in Nepal and China [19,59]. This result could be explained by the Theory of Reasoned Action [60], in which a person's attitude, combined with subjective norms, forms their behavioural intention. If a youth has a friend who uses maternal care services or STI/HIV testing, the youth is more likely to also use that service, either through direct encouragement, or the influence of social norms.

Media exposure was consistently associated with a higher odds of accessibility to, and utilization of RH services and a lower odds of having an unmet need for these services by the youths in our study. Media exposure was also shown to be a significant factor for access to SRH information among male youths in India [61], SRH information and contraceptives use in China [62] and contraceptives use in the Philippines [33]. In addition, the media for SRH information was shown to be the most common source for unmarried migrant youths in three 
major cities of China [63]. These results indicate that media such as books, radio, television and the Internet are important for promoting utilization of $\mathrm{RH}$ services among young people.

\section{Strengths and limitations}

A holistic view of the accessibility to and utilization of $\mathrm{RH}$ services and youth's unmet needs towards $\mathrm{RH}$ services was elicited in our study. The challenges and factors hindering access to RH services among youths living in hardto-reach, resource-limited suburban communities were also highlighted. The questions used in the questionnaire were modified from the International Demographic Health Survey and we also used a multidimensional approach for accessibility to RH services, i.e. geographical and financial aspects. In addition, all outcome measures were based on either standard definitions or actual needs of the youths. The triangulation of factors associated with outcomes identified from regression analysis was consistent with youth's own reasons. There were some limitations in our study. First, the three main outcomes were obtained from the youth's own perceptions and responses, and were not objectively measured or confirmed by medical reports. However, anonymity and confidentiality were stressed and the youths were encouraged to answer all questions truthfully. Second, the results cannot be generalized to all youths living outside resource-limited communities because the demographic and socio-economic characteristics of youths living outside our study area may be different. Third, even though the community leaders, with the help of municipal authorities, provided a list of all youths living in their communities, it is possible that some youths may have not been included in the lists. Lastly, the level of unmet need for STI/HIV testing services was not assessed according to the youth's risky sexual behaviours since sexual behaviour is a culturally sensitive issue in Myanmar.

\section{Conclusions}

Despite the high availability of RH services, accessibility to and utilization of the services among youths in the study area were unsatisfactory. The levels of unmet need for RH services, especially family planning, were alarmingly high. Common associated factors of access to, utilization of and unmet need for RH services were place of residence, marital status, exposure to mass media, knowledge about the services and providers and perceived norm of peer exposure to RH services.

Financial constraint and affordability of youths to access and utilize RH services is an urgent issue for national policy makers and all stakeholders. Improvement of youth's knowledge about the existence of RH services is essential. Recent RH services should be tailored to the special needs of adolescents and unmarried youths. Dissemination of SRH information via popular mass media, such as television, and formal and informal education programs to enhance utilization and decrease unmet needs in these resource-limited areas is strongly advised. Further studies should emphasize on the effectiveness of the mass media on enhancing utilization of those services among youths in these areas.

\section{Competing interests}

The authors declare that there are no competing interests concerning this research article.

\section{Authors' contributions}

PPTZ designed the study, conducted the data collection process, analyzed and interpreted the data, and prepared the manuscript. TL provided supervision on all aspects of the study and manuscript preparation. $\mathrm{TH}$ helped to conceptualize the study, supported the data collection process and commented on the manuscript. EM helped with data management, statistical analysis and manuscript preparation. All authors read and approved the final manuscript.

\section{Acknowledgements}

This study was a part of the thesis of the first author to fulfil the requirement of the Ph.D. degree in Epidemiology at Prince of Songkla University. Funding support for this study was provided by the World Health Organization through special program of Research, Development, and Research Training in Human Reproduction (WHO/HRP). We wish to acknowledge the authorities from the Ministry of Health, Myanmar and the Director General of Department of Medical Research (Upper Myanmar) for allowing us to conduct the study. Our sincere thanks are directed to the five Township Medical Officers of Mandalay City and research officers and assistants from Department of Medical Research (Upper Myanmar) for their kind help and cooperation with data collection. Our thanks go to the Discipline of Excellence in Epidemiology, Faculty of Medicine, Prince of Songkla University for providing financial support to the first author during her study period.

\section{Author details}

${ }^{1}$ Department of Medical Research (Upper Myanmar), Pyin Oo Lwin, Myanmar. Epidemiology Unit, Faculty of Medicine, Prince of Songkla University, Hat Yai, Songkhla 90110, Thailand. ${ }^{3}$ Ministry of Health, Nay Pyi Taw, Myanmar.

Received: 15 May 2012 Accepted: 11 December 2012

Published: 15 December 2012

\section{References}

1. World Population Reference Bureau: World Population Data Sheet; 2009 [http://www.prb.org/Publications/Datasheets/2009/2009wpds.aspx].

2. United Nations, Department of Economic and Social Affairs: World Population Monitoring 2002: Reproductive Right and Reproductive Health; 2004 [http://www.un.org/esa/population/publications/2003monitoring/ WorldPopMonitoring_2002.pdf].

3. Stidham HK, Moreau C, Trussell J: Discouraging trends in reproductive health service use among adolescent and young adult women in the USA, 2002-2008. Hum Reprod 2011, 26:2541-2548.

4. Rahman M, Haque SE, Mostofa MG, Tarivonda L, Shuaib M: Wealth inequality and utilization of reproductive health services in the Republic of Vanuatu: insights from the multiple indicator cluster survey, 2007. Int J Equity Health 2011, 10(58):58.

5. Braeken D, Rondinelli I: Sexual and reproductive health needs of young people: matching needs with systems. Int J Gynaecol Obstet 2012, 119(Suppl 1):S60-S63. Aug 11.

6. Izugbara CO, Ngilangwa DP: Women, poverty and adverse maternal outcomes in Nairobi, Kenya. BMC Womens Health 2010, 10(33):33.

7. Leon Carmona JC, Hernandez Alvarez LA, Hernandez Hernandez MA: Effect of sociocultural factors on maternal and perinatal morbidity with or without mortality among adolescents seen in 3 states of the Mexican Republic. Ginecol Obstet Mex 2002, 70:320-327.

8. Pathak PK, Singh A, Subramanian SV: Economic inequalities in maternal health care: prenatal care and skilled birth attendance in india. PLOS One 2010, 5:112-115. 
9. Ziraba AK, Madise N, Mills S, Kyobutungi C, Ezeh A: Maternal mortality in the informal settlements of Nairobi city: what do we know? Reprod Health 2009, 6:112-117.

10. Simoes PP, Almeida RM: Geographic accessibility to obstetric care and maternal mortality in a large metropolitan area of Brazil. Int J Gynaecol Obstet 2011, 112:25-29.

11. Mayor S: Pregnancy and childbirth are leading causes of death in teenage girls in developing countries. BMJ 2004, 328:1152.

12. Atuyambe L, Mirembe F, Tumwesigye NM, Annika J, Kirumira EK, Faxelid E: Adolescent and adult first time mothers' health seeking practices during pregnancy and early motherhood in Wakiso district, central Uganda. Reprod Health 2008, 5:13-19.

13. Besculides M, Laraque F: Unintended pregnancy among the urban poor. J Urban Health 2004, 81:340-348.

14. Kaljee LM, Green M, Riel R, Lerdboon P, Tho LH, Thoa LTK, et al: Sexual stigma, sexual behaviors, and abstinence among vietnamese adolescents: implications for risk and protective behaviors for HIV, STIs, and unwanted pregnancy. J Assoc Nurses AIDS Care 2007, 18:48-59.

15. Singh S: Global consequences of unsafe abortion. Womens Health (Lond Engl) 2010, 6:849-860.

16. Adinma Jl, Adinma ED: Impact of reproductive health on socio-economic development: a case study of Nigeria. Afr J Reprod Health 2011, 15:7-12.

17. Hazarika I: Women's Reproductive health in slum populations in India: evidence from NFHS-3. J Urban Health 2010, 87:264-277

18. Gakidou E, Vayena E: Use of modern contraception by the poor is falling behind. PLoS Med 2007, 4(2): e31.

19. Regmi PR, van Teijlingen E, Simkhada P, Acharya DR: Barriers to sexual health services for young people in Nepal. J Health Popul Nutr 2010, 28:619-627.

20. Burma Economy; 2012 [http://www.theodora.com/wfbcurrent/burma/ burma_economy.html].

21. Henshaw SK: Factors hindering access to abortion services. Fam Plann Perspect 1995, 27(2):54-58, 87

22. Chayovan N, Hermalin Al, Knodel J: Measuring accessibility to family planning services in rural Thailand. Stud Fam Plann 1984, 15:201-211.

23. Mroz TA, Bollen KA, Speizer IS, Mancini DJ: Quality, accessibility, and contraceptive use in rural Tanzania. Demography 1999, 36:23-40.

24. Islam MS, Asktar S: Measuring physical accessiblity to health facilities: a case study on Khunla City. World Health Popul 2011, 12:123-127.

25. Gage AJ, Guirlene CM: Effects of the physical accessibility of maternal health services on their use in rural Haiti. Popul Stud (Camb) 2006 60:271-288

26. Tuladhar JM: Effect of family planning availability and accessibility on contraceptive use in Nepal. Stud Fam Plann 1987, 18:49-53.

27. Statistics Indonesia (Badan Pusat Statistik_BPS) and Macro International: Indonesia Demographic and Health Survey 2007. Calverton, Maryland, USA BPS and Macro International; 2008 [http://www.measuredhs.com/pubs/pdf/ FR218/FR218\%5B27August2010\%5D.pdf]

28. WHO: Unmet Need for Family Planning; 2012 [http://www.who.int/ reproductivehealth/topics/family_planning/unmet_need_fp/en/index.html].

29. Gulliford M, Figueroa-Munoz J, Morgan M, Hughes D, Gibson B, Beech R, et al: What does 'access to health care' mean? J Health Serv Res Policy 2002, 7:186-188.

30. Acuna DL, Gattini C, Pinto M, Andersson B: Access to and finances of health care: ways to measure and improve inequites. In Equity in Health: Pan American Health Organization; 2001:115-127. Views from the Pan American Sanitary Bureau. Occasional Publication No. 8.

31. Ray N, Ebener S: Computing geographic coverage and accessibility to health care services using anisotropic movement of patients. Int J Health Geogr 2008, 7:63-68.

32. Htay T, Gardner M: Service Factors Affecting Access and Choice of Contraceptives, Myanmar; 2012 [http://www.cicred.org/Eng/Seminars/Details/ Seminars/Bangkok2002/33BangkokTheinTheinHtayGardner.pdf].

33. Becker S, Peters DH, Gray RH, Gultiano C, Black RE: The determinants of use of maternal and child health services in Metro Cebu, the Philippines. Health Transit Rev 1993, 3:77-89.

34. Heard NJ, Larsen U, Hozumi D: Investigating access to reproductive health services using GIS: proximity to services and the use of modern contraceptives in Malawi. Afr J Reprod Health 2004, 8:164-179.

35. Kurtz LC, Sword W, Ciliska D: Urban women's socioeconomic status, health service needs and utilization in the four weeks after postpartum hospital discharge: findings of a Canadian cross-sectional survey. BMC Health Serv Res 2008, 8:203.
36. Fotso JC, Ezeh AC, Essendi H: Maternal health in resource-poor urban settings: how does women's autonomy influence the utilization of obstetric care services? eprod Health 2009, 6:9.

37. Yao J, Murray AT, Agadjanian V, Hayford SR: Geographic influences on sexual and reproductive health service utilization in rural Mozambique. Appl Geogr 2012, 32:601-607.

38. Kesterton AJ, Cleland J, Sloggett A, Ronsmans C: Institutional delivery in rural India: the relative importance of accessibility and economic status. BMC Pregnancy Childbirth 2010, 10:30.

39. Chen B, Lu YN, Wang HX, Ma QL, Zhao XM, Guo JH, et al: Sexual and reproductive health service needs of university/college students: updates from a survey in Shanghai. China Asian J Androl 2008, 10:607-615.

40. Rahman M, Nakamura K, Seino K, Kizuki M: Intimate partner violence and use of reproductive health services among married women: evidence from a national Bangladeshi sample. BMC Publ Health 2012, 12:913.

41. Tangmunkongvorakul A, Banwell C, Carmichael G, Utomo ID, Seubsman SA, Kelly $M$, et al: Use and perceptions of sexual and reproductive health services among northern Thai adolescents. Southeast Asian J Trop Med Public Health 2012, 43:479-500.

42. Namasivayam A, Osuorah DC, Syed R, Antai D: The role of gender inequities in women's access to reproductive health care: a populationlevel study of Namibia, Kenya, Nepal, and India. Int J Womens Health 2012, 4:351-364.

43. Hall KS, Moreau C, Trussell J: Determinants of and disparities in reproductive health service use among adolescent and young adult women in the United States, 2002-2008. Am J Public Health 2012, 102:359-367.

44. Hall KS, Moreau C, Trussell J: Associations between sexual and reproductive health communication and health service use amongUS Adolescent women. Perspect Sex Reprod Health 2012, 44:6-12.

45. Frost JJ: Trends in US women's use of sexual and reproductive health care services, 1995-2002. Am J Public Health 2008, 98:1814-1817.

46. Islam M: Progress towards achieving Millennium Development Goal 5 in South-East Asia. BJOG 2011, 118(Suppl 2):6-11

47. Panitchpakdi P, Podhipak A, Sein UK, Kywe B: Family planning: knowledge, attitudes and practice survey in Zigone, Myanmar. Southeast Asian J Trop Med Public Health 1993, 24:636-646.

48. Rafiqul HC: Unmet Need for Contraception in South Asia: Levels, Trends and Determinents. Asia- Pacific Population Journal 2001, 16:3-22.

49. Myo MM, Liabsuetrakul T: Factors influencing married youths' decisions on contraceptive use in a rural area of Myanmar. Southeast Asian J Trop Med Public Health 2009, 40:1057-1064

50. Rosenstock IM, Strecher VJ, Becker MH: Social learning theory and the Health Belief Model. Health Educ Q 1988, 15:175-183.

51. UNFPA, Ministry of Health (Myanmar): A Reproductive Health Needs Assessment in Myanmar. [http://countryoffice.unfpa.org/myanmar/? publications $=1471]$.

52. Tint HS, Thaw P, Oo YN, Zaw KK, Sein T, Tun T: Sexual and reproductive health needs of vulnerable youth in Myanmar. Southeast Asian J Trop Med Public Health 2008, 39:1126-1138.

53. Cheng YM, Wang XY, LV YH, Cai YM, Li Y, Guo X, et al: Study on the risk factors of repeated abortion among unmarried adolescents. Zhonghua Liu Xing Bing Xue Za Zhi 2006, 27:669-672.

54. Forrest JD: Epidemiology of unintended pregnancy and contraceptive use. Am J Obstet Gynecol 1994, 170:1485-1489.

55. Sychareun V: Meeting the contraceptive needs of unmarried young people: attitudes of formal and informal sector providers in Vientiane Municipality. Lao PDR. Reprod Health Matters 2004, 12:155-165.

56. Nalwadda G, Mirembe F, Tumwesigye NM, Byamugisha J, Faxelid E: Constraints and prospects for contraceptive service provision to young people in Uganda: providers' perspectives. BMC Health Serv Res 2011, 11:220.

57. Sedgh $G$, Singh $S$, Shah $H_{\text {, Ahman }}$, Henshaw SK, Bankole A: Induced abortion: incidence and trends worldwide from 1995 to 2008. Lancet 2012, 379:625-632.

58. Tegegn A, Yazachew M, Gelaw Y(E): Reproductive Health Knowledge and Attitude among Adolescents: A community based study in Jimma Town, Southwest Ethiopia. Ethiopian Journal of Health Development 2008, 22:144-150.

59. Yang C, Latkin C, Luan R, Nelson K: Peer norms and consistent condom use with female sex workers among male clients in Sichuan province. China. Soc Sci Med 2010, 71:832-839. 
60. Fishbein M, Aizen I: Belief, Attitude, Intention, and Behavior: An Introduction to Theory and Research. Reading, MA: Addison-Wesley; 1975.

61. Char A, Saavala M, Kulmala T: Assessing young unmarried men's access to reproductive health information and services in rural India. BMC Publ Health 2011, 11:476.

62. Lou C, Cheng Y, Gao E, Zuo X, Emerson MR, Zabin LS: Media's contribution to sexual knowledge, attitudes, and behaviors for adolescents and young adults in three Asian cities. J Adolesc Health 2012, 50:S26-S36.

63. Liu Z, Zhu M, Dib HH, Li Z, Shi S, Wang Z: RH knowledge and service utilization among unmarried rural-to-urban migrants in three major cities. China. BMC Public Health 2011, 11:74-79.

doi:10.1186/1472-6963-12-458

Cite this article as: Thin Zaw et al.: Equity of access to reproductive health services among youths in resource-limited suburban

communities of Mandalay City, Myanmar. BMC Health Services Research 2012 12:458

\section{Submit your next manuscript to BioMed Central and take full advantage of:}

- Convenient online submission

- Thorough peer review

- No space constraints or color figure charges

- Immediate publication on acceptance

- Inclusion in PubMed, CAS, Scopus and Google Scholar

- Research which is freely available for redistribution 